\title{
Degradation of organic matter using a submerged micro bubble diffuser in a biological wastewater treatment system
}

\author{
S. R. M. Kutty ${ }^{1}$, F. E. W. Winarto ${ }^{2}$, S. I. U. Gilani ${ }^{2}$, \\ A. A. Anizam ${ }^{1}$, W. W. Z. Karimah ${ }^{1}$ \& M. H. Isa ${ }^{1}$ \\ ${ }^{I}$ Civil Engineering Department, Universiti Teknologi, Malaysia \\ ${ }^{2}$ Mechanical Engineering Department, Universiti Teknologi, Malaysia
}

\begin{abstract}
.
In most biological wastewater treatment systems, aeration is provided using millimetre diffusers of various sizes. The aeration is to provide mixing, as well as oxygen, for the microorganisms in the degradation of organic matter. In this study, the effectiveness of using micro diffusers in the degradation of organic matter was evaluated. Two reactors A and B, of size 140x140x500 mm, were constructed using Perspex to treat municipal wastewater. Aeration in reactors A and $\mathrm{B}$ was provided using a millimetre diffuser and a micro diffuser, respectively. The diffusers consist of perforated aluminium plate to generate millimetre bubbles and sintered porous glass to generate micro bubbles. Compressed air was forced through two parallel flow meters at a flow rate of 2.5 $\mathrm{L} / \mathrm{min}$. Biomass for both reactors were acclimatized prior to treating the municipal wastewater in the reactors. Two batch experiments were conducted at $26^{\circ} \mathrm{C}$ for the estimation of the kinetic parameters for the degradation of organic matter. Samples were evaluated for chemical oxygen demand (COD) and soluble chemical oxygen demand (sCOD) for both reactors at approximately 1 hour, 3 hours, and 6 hours, respectively, until 48 hours, for each batch of experiment. From the results of the study, it was found that for the micro and millimetre diffusers, the degradation kinetic parameter $\mathrm{k}_{\mathrm{COD}}$ was 0.041 and 0.028 , respectively, for COD and $k_{S C O D}$ was 0.060 and 0.044 , respectively, for SCOD. On average, the micro and millimetre diffusers removed COD at approximately $87 \%$ and $81 \%$, respectively, and removed sCOD at approximately $91 \%$ and $75 \%$, respectively. It can be concluded that the use of a micro diffuser can provide a higher degradation of organic matter.
\end{abstract}


Keywords: micro air bubbles, COD, sCOD, DO, kinetics evaluation.

\section{Introduction}

Air is often injected into wastewater to create an aerobic condition for the bacterial degradation of organic matter. This provides mixing, as well as oxygen, for dissolved and suspended organic matter sufficiently and for the oxidation of organic matter, respectively [1]. Aeration in wastewater treatment is mostly provided through subsurface and mechanical systems. A subsurface system is where air is introduced into the wastewater by diffusers or devices submerged in the wastewater, usually at the bottom of the aeration tank. Mechanical systems, on the other hand, agitate the wastewater using mechanical devices, such as propellers and blades, to introduce air from the atmosphere [2]. A coarse bubble diffuser is a type of subsurface aerator that involves a huge input of energy and the oxygen transfer is sometimes inadequate to meet the process needs. This is due to the turbulence effect and the movement speed that is caused by the increased size of spherical air bubbles when it moves upward. The size of the air bubbles is one of the important factors for minimizing the turbulence effect and decreasing movement speed (they take more time to reach water surface). In addition, lifting the suspended particles requires a laminar air bubble rise [3]. Micro air bubbles provide a larger interfacial area for oxygen transfer, as the air bubble provides a large surface area to volume ratio. Decreasing the bubble diameter from $2.5 \mathrm{~mm}$ to $0.5 \mathrm{~mm}$ would increase the interfacial contact area between the air and water twenty-five times for spherical bubbles. This helps to fulfil the goal of aeration, which is to dissolve oxygen into water [4]. Oxygen diffusion is influenced by the interaction between air and the wastewater. Degradation of organic matter and nitrification depends on the diffusion rate of oxygen into the water. By enhancing the oxygen diffusion rate, higher and faster organic matter removal can be achieved [5]. In the diffusion process, air in the atmosphere has a higher concentration of oxygen than water; hence oxygen diffuses or is pushed from the air into the water [1].

Submerged air diffusers are mostly used to increase dissolved oxygen (DO) levels and promote water circulation. Air or pure oxygen bubbles are released at depth, producing a free, turbulent bubble-plume that rises to the water surface through buoyant force [6]. As the bubble plume ascends, it entrains water, causing vertical circulation and lateral surface spreading. Oxygen is transferred to the water across the bubble interfaces as the bubbles rise from the diffuser to the top water surface. There are two main interfaces over which oxygen transfer occurs: across the bubble interfaces as the bubbles rise through the water column and across the water surface at the air-water interface [6]. The bubble-transfer rate involves some additional considerations. The liquid-phase equilibrium concentration of a given bubble is not only a function of temperature and atmospheric pressure, but also hydrostatic pressure and gas-phase oxygen composition. As the bubbles rise, bubble-water gas transfer of oxygen, nitrogen, argon, carbon dioxide, and trace gases occurs due to a concentration gradient between the equilibrium bubble concentration and the ambient water 
concentration. Over depth, the bubble-water transfer of all gases affects the gasphase oxygen composition and the equilibrium oxygen concentration. The equilibrium oxygen concentration inside a bubble also depends on the gas flow rate and the changing bubble-water transfer coefficient over depth $[4,5]$. The effect of DO on nitrification is affected by the activated-sludge floc size and the density and total oxygen demand of the mixed liquor [1]. Nitrifying bacteria are distributed within a floc containing heterotrophic bacteria and other solids, with floc diameters ranging from 100 to $400 \mu \mathrm{m}$. Oxygen from the bulk liquid diffuses into floc particles and bacteria deeper within the floc are exposed to lower DO concentrations. Therefore, a higher bulk liquid DO concentration is needed to maintain the same internal floc DO concentration and subsequent nitrification rate [1]. Biodegradation of organic matter is accelerated by increased temperature $\left(20^{\circ} \mathrm{C}\right.$ to $\left.40^{\circ} \mathrm{C}\right)$, but the amount of stoichiometric oxygen needed has to be achieved at first. By using micro bubble aeration, the diffused oxygen can be preserved [7]. Dissolved oxygen should be enough to support the biodegradation process. Micro bubbles' aeration increase the oxygen diffusion process. Studies have shown that sufficient aeration is required for significant biodegradation of various wastes, such as olive oil husks, PCP (Pentachlorophenol), diesel oil and gasoline contaminated water and petroleum waste [8-12].

Meanwhile, coarse bubbles were found to use more energy and sometimes oxygen absorption is inadequate because the bubbles were quickly raised to the top water surface. However, micro bubbles move more slowly and take more time to reach the water top surface. This gives adequate time for the transfer of oxygen from the bubbles to the water medium since there is a longer contact time. Oxygen transfer was also found to be enhanced with or without surfactants [13].

\section{Objectives}

The objective of this study is to evaluate the effectiveness of micro bubbles in reducing COD in wastewater.

\section{Experimental setup}

\subsection{Reactor configuration}

An experimental setup using two vertical reactors A and B, each of $140 \mathrm{~mm}$ length, $140 \mathrm{~mm}$ width and $500 \mathrm{~mm}$ height were used. A perforated aluminium disc ( $3 \mathrm{~mm}$ thick) with holes ranging in diameter from 0.1 to $0.4 \mathrm{~mm}$ was used to create millimetre size air bubbles in reactor A. Porous sintered glass with porosities in the range of 10-16 micron was used to produce micro bubbles in reactor B. Compressed air at a pressure of $63 \mathrm{kPa}$ and a flow rate of $2.5 \mathrm{~L} / \mathrm{min}$ was forced through the diffusers at the bottom of both reactors. Figure 1 shows the schematic diagram of the experimental apparatus. 


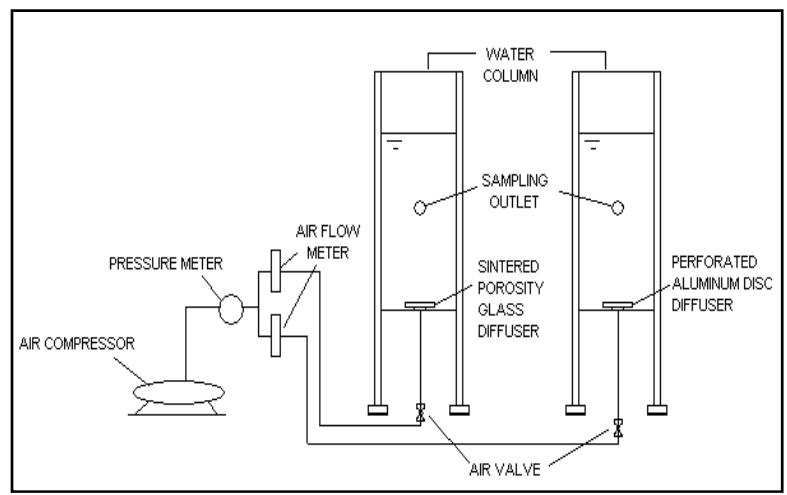

Figure 1: $\quad$ Schematic diagram of the experimental apparatus.

\subsection{Experimental procedure}

Biomass for the degradation of organic matter was taken from a municipal activated sludge plant and placed in both reactors. The biomass was acclimatized for 2 weeks prior to experimentation. $5 \mathrm{~L}$ of raw wastewater sample was treated in both reactors. Aeration was then provided through the perforated aluminium disc diffuser and the micro sintered glass bubble diffuser in reactors A and B, respectively. Aeration was continuously provided throughout the study. Samples were collected at regular time intervals of 1, 3, 6, 24 hours and then every 6 hours thereafter. The samples were settled, filtered, diluted $(1: 20)$ and tested for COD and sCOD.

\section{Results and discussion}

\subsection{COD removal}

The removal of COD throughout the study period was plotted in Figure 2a. It can be observed that the COD of the wastewater dropped gradually throughout the study period. Samples taken from Reactor B which utilized the micro diffuser showed lower effluent COD concentrations than samples from Reactor A which utilized the millimetre diffuser. It can be observed that the degradation of COD is higher after 12 hours of aeration. The experimental data was expressed in the form of the kinetic modelling so that the coefficient rate, $k$ or the rate of organic matter removal can be calculated to determine the effectiveness of the micro diffuser. After obtaining the coefficient rate, $k$ value, the kinetic modelling graph was plotted for both COD as shown in Figure 2b. From the theoretical study, it was found that, the COD degradation kinetic parameter, $k_{\text {cod }}$ was 0.041 and 0.028 , respectively, for the micro and millimetre diffusers. Statistical t-tests conducted on both experimental and theoretical values indicated that there is a significant difference between effluent COD from micro- and millimetre diffuser reactors at 5\% level of significance. On average, micro and millimetre diffusers removed COD at approximately $87 \%$ and $81 \%$, respectively, 


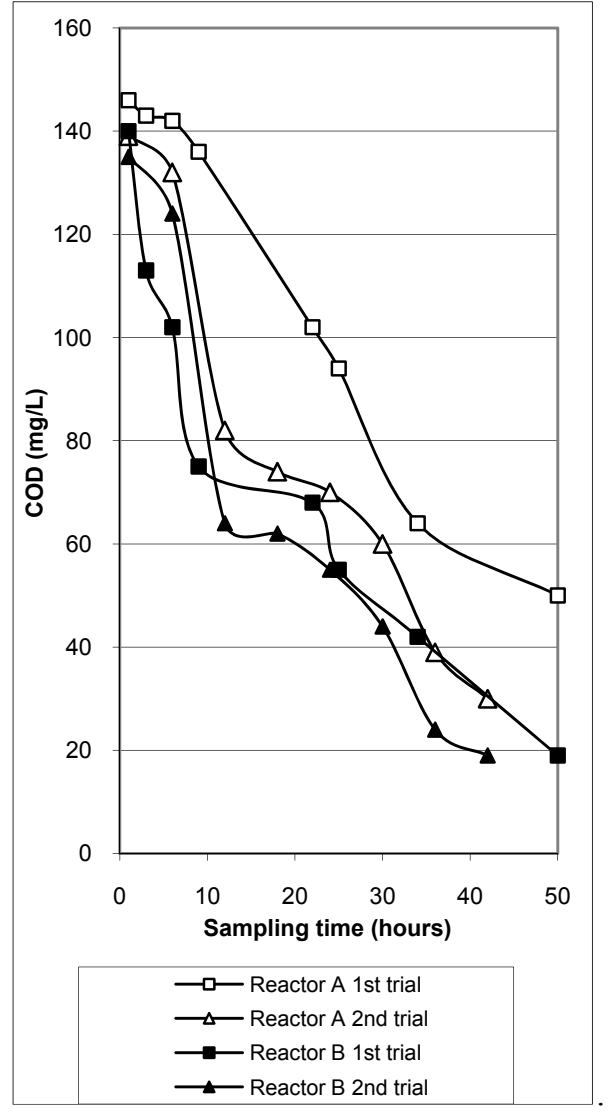

a.

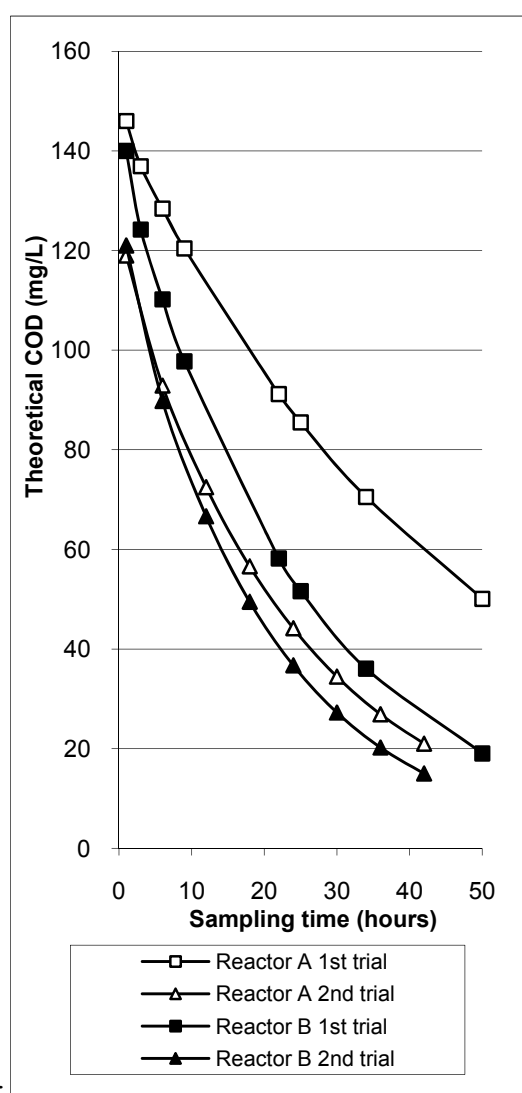

b.

Figure 2: Graph of: a. experimental b. theoretical COD value vs. sampling time (hrs).

The experimental and theoretical COD degradation rate throughout the study period was plotted in Figure $3 \mathrm{a}$ and Figure $3 \mathrm{~b}$, respectively. It can also be observed that the degradation of COD was at a higher rate during the initial stage of the study for Reactor B which utilized micro diffuser compared to Reactor A which utilized millimetre diffuser. This indicates that faster COD degradation rate was achieved using the micro diffuser. The average degradation rate from $30-42 \mathrm{hr}$ of aeration was found to be $3 \mathrm{mg} / \mathrm{L} . \mathrm{hr}$ and $2.48 \mathrm{mg} / \mathrm{L} . \mathrm{hr}$, for micro and millimetre diffuser, respectively.

Statistical analysis conducted indicated that both experimental and theoretical COD degradation rates were significantly different at $10 \%$ level of significance for both diffusers. 


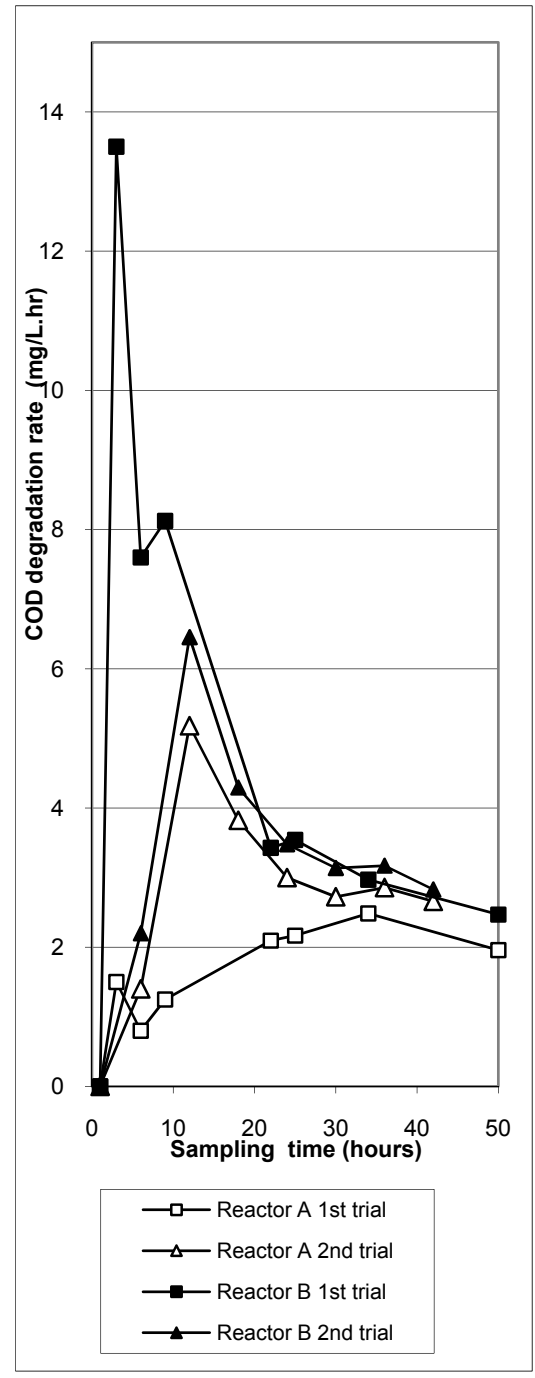

a.

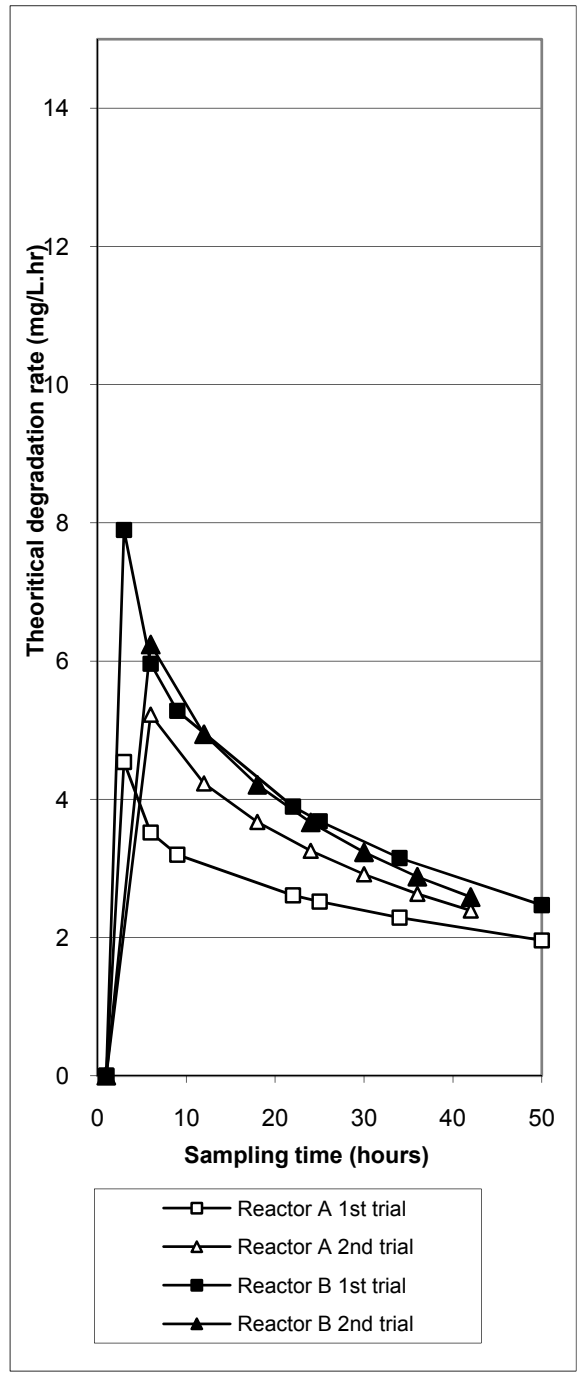

b.

Figure 3: Degradation rate of COD: a. experimental b. theoretical.

\section{$4.2 \mathrm{sCOD}$ removals}

The experimental and theoretical sCOD degradations were plotted in Figure 4a and $4 \mathrm{~b}$, below. It can be observed from Figure $4 \mathrm{a}$ that the degradation of SCOD is highest at approximately 10 hours of aeration. The final effluent sCOD for the reactors stabilized at approximately $20 \mathrm{mg} / \mathrm{L}$ and $6 \mathrm{mg} / \mathrm{L}$, for millimetre and micro diffusers, respectively at the end of the sampling period. It can be observed that effluent sCOD from the micro diffuser reactor (Reactor B) stabilized at approximately 24 hours of aeration. The experimental sCOD also 
closely follows the theoretical sCOD plotted in Figure 4b with sCOD degradation rate $k_{S C O D}$ to be 0.060 and 0.044 , for micro and millimetre diffuser, respectively. On average, micro and millimetre diffusers removed sCOD at approximately $91 \%$ and $75 \%$, respectively. Statistical t-tests conducted on both experimental and theoretical values indicated that there is a significant difference between effluent sCOD from micro- and millimetre diffuser reactors at 5\% level of significance.

The experimental and theoretical sCOD degradation rate throughout the study period was plotted in Figure $5 \mathrm{a}$ and Figure $5 \mathrm{~b}$, respectively. It can also be observed that the degradation of SCOD was at a higher rate during the initial stage of the study for Reactor B which utilized micro diffuser compared to Reactor A which utilized millimetre diffuser. This indicates that faster SCOD degradation rate was achieved using the micro diffuser. The average degradation rate from $30-42 \mathrm{hr}$ of aeration was found to be $3 \mathrm{mg} / \mathrm{L} . \mathrm{hr}$ and $2.5 \mathrm{mg} / \mathrm{L} . \mathrm{hr}$, for micro and millimetre diffuser, respectively.

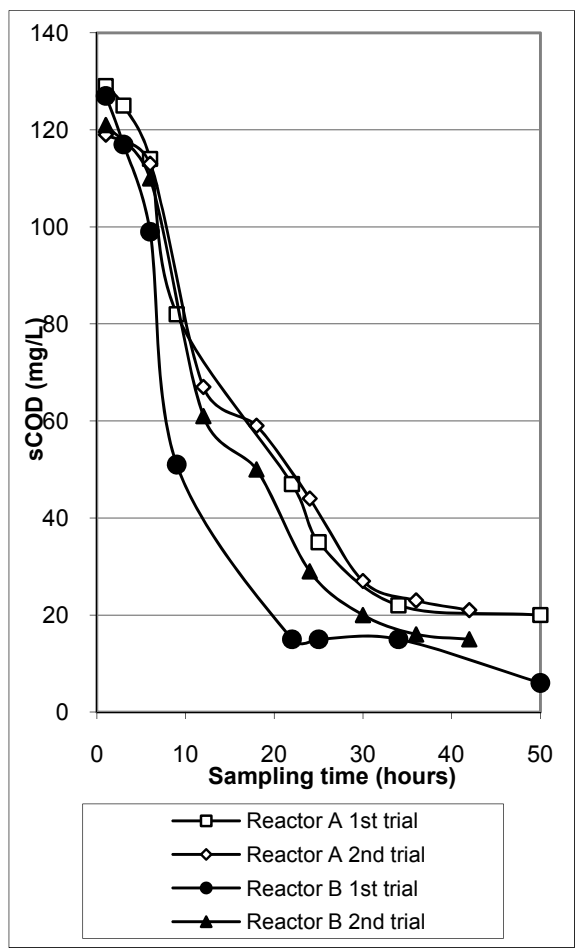

a.

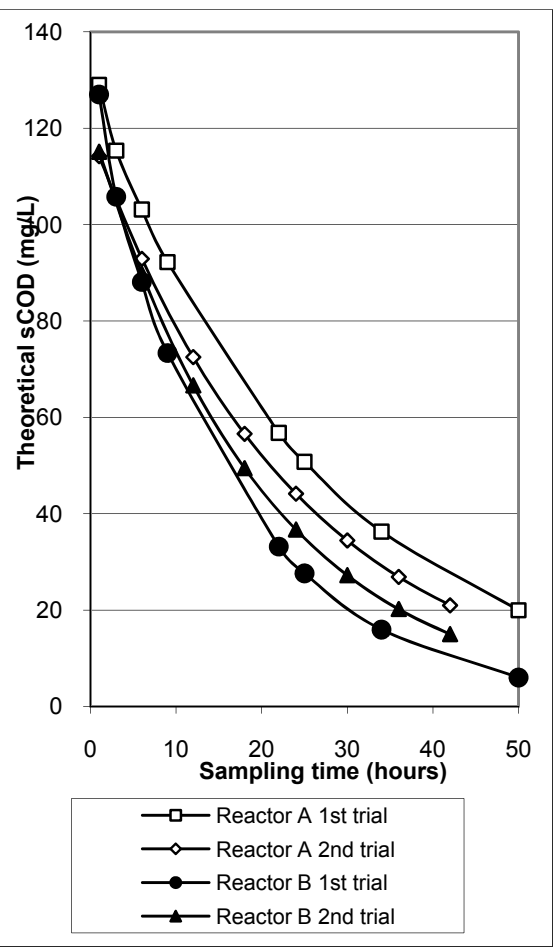

b.

Figure 4: Graph of: a. experimental sCOD vs. sampling time b. theoretical sCOD vs. sampling time. 


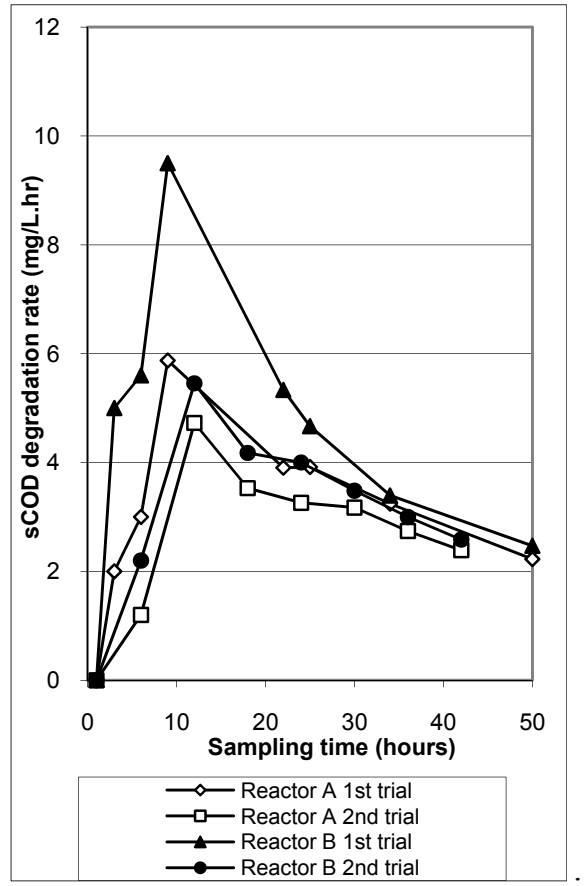

a.

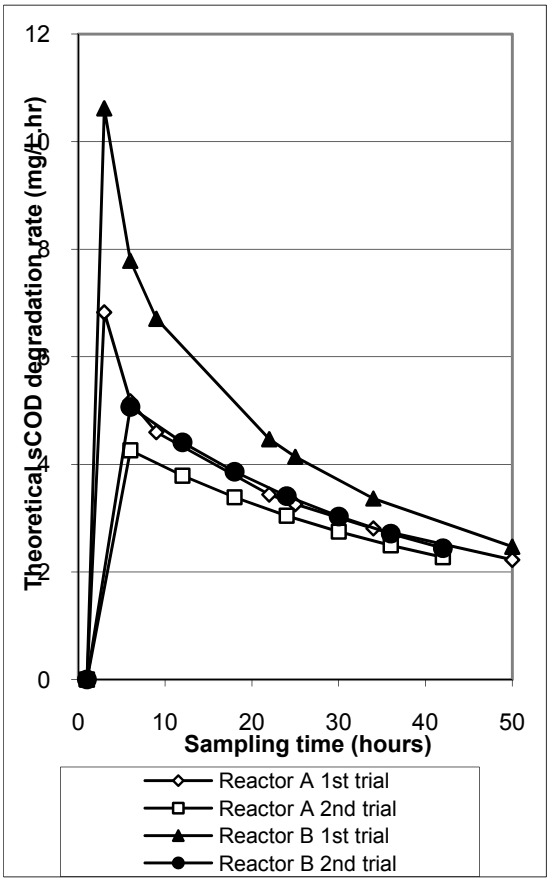

b.

Figure 5: Degradation of sCOD: a. experimental b. theoretical.

The experimental degradation rate also closely follows the theoretical degradation rate with the theoretical degradation rate from 30-42 $\mathrm{hr}$ of aeration found to be $3.03 \mathrm{mg} / \mathrm{L} . \mathrm{hr}$. and $2.6 \mathrm{mg} / \mathrm{L} . \mathrm{hr}$. (average of the values) for micro and millimetre diffuser, respectively. Statistical analysis conducted indicated that both experimental and theoretical sCOD degradation rates were significantly different at $10 \%$ level of significance for both diffusers.

\section{Conclusion}

From the study it was found that the reactor with micro-diffuser achieved higher percentage removals of COD and SCOD compared to the reactor with millimetre diffuser. Similarly, slightly higher degradation rates of COD and SCOD were achieved for the reactor using the micro diffuser. This shows that there is a potential use of the micro diffuser in wastewater treatment as higher rate of oxygen diffusion into the water can be achieved.

\section{References}

[1] Metcalf \& Eddy, 2004, "Wastewater Engineering Treatment and Reuse" Fourth Edition, New York, McGraw Hill Companies, Inc. 
[2] United States Environmental Protection Agency, 1999, "Wastewater Technology Fact Sheet Fine Bubble Aeration", Washington DC, EPA 832F-99-065.

[3] Gilani S.I.U. Winarto F.E.W., Rangkuti C. Aziz A.R., 2008. "Dynamic behaviour of air bubbles generated by a submerged micro hole diffuser in a water purification system". Icper, Kuala Lumpur, 2008.

[4] Burris W.A., 1999, "Discovery of factors affecting bubble size in water" Water technology, pp. 54-57.

[5] A. Nor-Anuar, Ujang Z., van Loosdrecht M.C.M., Olsson G., 2008, "Effects of aerated-mixing condition to the settling characteristics of aerobic granular sludge", Water resource.

[6] Fisher HB, List JE., Koh RCY., Imberger J., Brooks NH., 1979, “Mixing in inland and coastal water", San Diego. Academic Press.

[7] Liwarska-Bizukojc, Ledakowicz, 2003, "Stoichiometry of the aerobic biodegradation of the organic fraction of municipal solid waste (MSW)", Biodegradation 14, pp 51-56.

[8] Lopez Zavala Miguel Angel., 2002, “Onsite Wastewater Differentiable Treatment System (OWDTS), An Ecological Sanitation Alternative for Developing Countries", XXVIII Congreso Interamericano de Ingenieria Sanitaria Y Ambiental Cancun, Mexico, 27 al 31 de octubre.

[9] Baeta-Hall L., Ceu Saagua M., Bartolomeu M. L., Anselmo A. M., Rosa M. F., 2005, "Biodegradation of olive oil husks in composting aerated piles" Bioresource Technology 96, pp 69-78.

[10] Miller M.N., Stratton G. W., Murray G., 2004, "Effects of Soil moisture and Aeration on the Biodegradation of pentachlorophenol contaminated soil”, Bull. Environ. Contam. Toxicol 72, Springer-Verlag New York Inc. pp 101-108.

[11] Vieira P.A., Vieira R.B., Faria S., Ribeiro E.J., Cardoso V. L., 2009, "Biodegradation of diesel oil and gasoline contaminated effluent employing intermittent aeration", Journal of Hazardous Material, 168, pp 1366-1372.

[12] Ururahy A. F.P., Marins M.D.M., Vital R. L., Gabardo I.T., Nei Pereira Jr., 1998 "Effect of aeration on biodegradation of petroleum waste", Revista de Microbiologia, pp 1-13

[13] Chun Liu, Lie Zhang, Jing Liang Yang, Jian Bo Guo, Zai Xing Lin, 2009, "Effect of surfactants on oxygen transfer in microbubble aeration", Energy and environment Technology, International conference on energy and environment technology, vol 2, pp 531-534 